\title{
Assessment of the Effects of Tribulus Terrestris on Sexual Function of Menopausal Women
}

\section{Avaliação dos efeitos do Tribulus Terrestris na sexualidade de mulheres no climatério}

\author{
Sóstenes Postigo ${ }^{1}$ Sônia Maria Rolim Rosa Lima ${ }^{1}$ Silvia Saito Yamada ${ }^{1}$ Benedito Fabiano dos Reis ${ }^{2}$ \\ Gustavo Maximiliano Dutra da Silva ${ }^{3}$ Tsutomu Aoki ${ }^{1}$ \\ ${ }^{1}$ Department of Obstetrics and Gynecology, School of Medical \\ Sciences, Santa Casa de São Paulo-FCMSCSP, São Paulo, SP, Brazil \\ 2 Department of Obstetrics and Gynecology, Universidade do Vale Do \\ Sapucaí-UNIVAS, Minas Gerais (MG), Brazil \\ Address for correspondence Sóstenes Postigo, MD, MSc, School of \\ Medical Sciences, Department of Obstetrics and Gynecology, Santa \\ Casa de São Paulo -FCMSCSP, Rua Doutor Cesário Mota Jr., 61, São \\ Paulo (SP) 01221-020, Brazil (e-mail: sostenes.p@uol.com.br).
}

${ }^{3}$ Graduate Program, School of Medical Sciences, Santa Casa de São Paulo, São Paulo, SP; Universidade São Francisco Campus of Bragança Paulista, Bragança Paulista, SP, Brazil

Rev Bras Ginecol Obstet 2016;38:140-146.

\begin{abstract}
Keywords

- sexuality

- menopause

- physiological sexual dysfunction

- tribulus

- phytotherapeutic medicines

Objective The aim of this study was to study the effects of Tribulus terrestris on sexual function in menopausal women.

Methods This was a prospective, randomized, double-blind, placebo-controlled clinical trial that included 60 postmenopausal women with sexual dysfunction. The women were divided into two groups, placebo group and Tribulus group, and evaluated by using the Sexual Quotient-female version (SQ-F) and Female Intervention Efficacy Index (FIEI) questionnaires.

Results There was no significant difference between the groups in age, age at menopause, civil status, race, and religion. In the evaluation with the SQ-F questionnaire, there were significant differences between the placebo $(7.6 \pm 3.2)$ and Tribulus $(10.2 \pm 3.2)$ groups in the domains of desire and sexual interest $(p \leq 0.001)$, foreplay $(3.3 \pm 1.5$ versus $4.2 \pm 1.0)(p \leq 0.01)$, arousal and harmonious interaction with the partner $(5.7 \pm 2.1$ versus $7.2 \pm 2.6)(p \leq 0.01)$, and comfort in sexual intercourse $(6.5 \pm 2.4$ versus $8.0 \pm 1.9)(p \leq 0.01)$. There was no significant difference between the placebo and Tribulus groups in the domains of orgasm and sexual satisfaction $(p=0.28)$. In the FIEI questionnaire, there was a significant improvement $(p<0.001)$ in the domains of vaginal lubrication during coitus and/or foreplay (20 versus $83.3 \%$ ), sensation in the genitalia during sexual intercourse or other stimuli (16.7 versus $76.7 \%$ ), sensation in the genital region ( 20 versus $70 \%$ ), sexual intercourse and/or other sexual stimulations ( 13.3 versus $43.3 \%$ ), and the ability to reach orgasm ( $20 \%$ versus 73.3\%). There was no significant difference in adverse effects between the two groups. Conclusions After 90 days of treatment, at the doses used, we found Tribulus terrestris to be effective in treating sexual problems among menopausal women.
\end{abstract}

received

November 18, 2015

accepted

December 2, 2015

published online

February 22, 2016
DOI http://dx.doi.org/

$10.1055 / \mathrm{s}-0036-1571472$.

ISSN 0100-7203.
Copyright $(2016$ by Thieme Publicações License terms

Ltda, Rio de Janeiro, Brazil

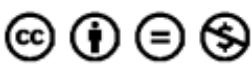




\section{Resumo}

\section{Palavras-chave}

- sexualidade

- menopausa

- disfuncão sexual fisiológica

- Tribulus

- medicamentos fitoterápicos
Objetivo Estudar os efeitos do Tribulus terrestris na função sexual de mulheres após a menopausa.

Métodos Ensaio clínico, prospectivo, randomizado, duplo-cego, placebo controlado, com 60 mulheres após a menopausa com disfunção sexual, divididas em dois grupos: Grupo Placebo e Grupo Tribulus, avaliadas através dos questionários Quociente Sexualversão Feminina (QS-F) e Female Intervention Efficacy Index (FIEI).

Resultados Não houve diferença significante entre os grupos quanto à idade, idade de menopausa, estado civil, raça e religião. Na avaliação do questionário QS-F houve diferença significante entre os grupos Placebo $(7,6 \pm 3,2)$ e Tribulus $(10,2 \pm 3,2)$ nos aspectos desejo e interesse sexual $(p \leq 0,001)$, preliminares $(3,3 \pm 1,5$ versus $4,2 \pm 1,0)(p \leq 0,01)$, excitação da mulher e sintonia com o parceiro $(5,7 \pm 2,1$ versus $7,2 \pm 2,6)(p \leq 0,01)$ e no aspecto conforto na relação sexual $(6,5 \pm 2,4$ versus $8,0 \pm 1,9)(p \leq 0,01)$. $O$ aspecto orgasmo e satisfação sexual não houve diferença significante entre o Grupo Placebo e Tribulus $(p=0,28)$. No questionário FIEI houve melhora significante $(p<0,001)$ na lubrificação vaginal durante o coito e/ou preliminares (20 versus $83,3 \%$ ), na sensação nas genitálias durante a relação sexual ou outros estímulos (16,7 versus $76,7 \%$ ), na sensação na área genital (20 versus $70 \%$ ), nas relações sexuais e/ou outras estimulações sexuais (13,3 versus $43,3 \%$ ) e na capacidade de ter orgasmo (20\% versus $73,3 \%$ ). Quanto aos efeitos colaterais não houve diferença significante entre os dois Grupos.

Conclusões Após noventa dias, podemos concluir que o Tribulus terrestris nas doses utilizadas demonstrou ser efetivo no tratamento das queixas sexuais das mulheres após a menopausa.

\section{Introduction}

Sexuality is dynamic and alterable with time and may be addressed through different scientific angles: through the physiological and psychological aspects, as well as through interpersonal and intrapersonal relationships. Sexuality is directly influenced by sociocultural aspects, being addressed by the social sciences, human sciences (biological and genetic domains), and political sciences. Internal factors such as affectivity, intellect, cognition, and emotion, and external factors such as geography, religion, economic system, habits and customs, and the social and cultural environment also have an influence. Thus, it constitutes a global expression of personality and, although it varies among cultures and individuals, sexuality must be understood as an integral part of the global history of women. ${ }^{1,2}$

It is estimated that $43 \%$ to $88 \%$ of women have at least one complaint of a sexual problem during their lifetime. ${ }^{3}$ Sexual desire and arousal disorders are among the most common problems presented in gynecological clinics. ${ }^{4,5}$

In a study involving 2,708 Brazilian women, Abdo $^{6}$ showed that one-third had reduced or absent sexual desire, $\sim 26.2 \%$ could not reach orgasm, and $18 \%$ experienced pain during sexual intercourse. They also reported a gradual loss of sexual desire with age.

Decline in ovarian hormone function leads to significant changes in the internal and external genital organs, which can influence sexual response. However, organic modifica- tions that occur in women after menopause do not diminish sexual pleasure, but only slow the response. ${ }^{2,7}$

Several studies have confirmed the decline in sexual function associated with age and the progression of menopause. $^{3,7}$ Although the role of sex steroids in sexual function has been demonstrated, particularly in the stage of desire, the specific functions of sex steroids are unknown. ${ }^{8}$

The decrease in the serum androgen level in menopause may be associated with worsening of sexual dysfunction, with a correlation between sexual desire and free testosterone level. ${ }^{9}$

Testosterone has a primary role in maintaining sexual interest and motivation, ${ }^{4,10}$ and may restore desire and arousal, besides promoting the sexual fantasies of women who do not respond to estrogen alone. ${ }^{4}$

Medicinal plants were always used as therapeutic resources of great value. For a long time, the Western medical community did not give credibility to this practice for lack of scientific evidence. Since the 1980s, however, there was a larger investment in research with standard drugs and quality control. Phytotherapeutic agents have a high therapeutic index and their use is associated with a low incidence of adverse effects. ${ }^{2}$

Tribulus terrestris is a plant originally from India, widely used as a natural sexual stimulant in Chinese, Indian, and Greek traditional medicine. The current findings are limited to animal studies, which showed a significant increase in erectile function after the oral administration of the extract of the plant. ${ }^{11,12}$ Several studies have demonstrated that products derived from 
Tribulus can increase serum levels of endogenous testosterone, thus justifying the effects seen on erectile function, although it is not clear how Tribulus influences this increase. ${ }^{11,13,14}$

The main constituents of $T$. terrestris are steroids, saponins, flavonoids, and alkaloids. The hydrolyzed saponins are transformed into steroidal sapogenins, with antispasmodic and natriuretic properties, and increase the production of luteinizing hormone (LH), testosterone, estrogen, and other steroids. ${ }^{15}$

The extract obtained from the aerial parts of the dry plant contains furostanol-type steroidal glycosides (saponins), of which the predominant active component is protodioscin (PTN), which represents $45 \%$ of the extract. ${ }^{15,16}$ Other steroidal saponin glycosides have been described in the literature, including 3-O- $\beta$-D-glucopyranosyl (-- $>2)-\beta$-D-glucopyranosyl (1--4)- $\beta$-D-galactopyranoside and neo-hecogenin-3-O- $\beta$-Dglucopyranosyl (1-->4)- $\beta$-D-galactopyranoside. ${ }^{17}$

Steroidal saponins may be responsible for the intrinsic hormonal activity by directly stimulating responsive endocrine tissues such as the uterus and vagina. It was proposed that the active components of $T$. terrestris can be converted enzymatically to weak androgens similar to dehydroepiandrosterone (DHEA), which could, in turn, be converted to more powerful androgens such as testosterone in the gonads and peripheral tissues, correlating positively with sexual desire and sexual behavior. ${ }^{12,13,18,19}$

According to Arsyad $^{20}$ and Adimoelja, ${ }^{21}$ in a study performed in men, PTN increases the serum DHEA levels, resulting in improved self-esteem and general well-being. It acts by stimulating the production of the enzyme $5-\alpha-$ reductase, which converts testosterone into dihydrotestosterone, which has a fundamental role in the formation of blood cells and muscular development.

According to Adimoelja, ${ }^{21}$ testosterone and LH levels, as well as DHEA level, increased after the treatment of erectile dysfunction with PTN for 30 to 90 days in men. It should be noted that most of the studies found in the literature report the action of Tribulus in men. ${ }^{20,22}$

When we analyzed studies in women, we noted that Akhtari et $\mathrm{al}^{23}$ reported, in a randomized double-blind study, an improvement in sexual desire in women with hypoactive sexual desire disorder (HSDD).

The knowledge that androgens influence sexual desire $^{21,24-27}$ and the already known therapeutic properties of $T$. terrestris were the reasons for our interest in studying the effects of this phytotherapy in the treatment of sexual dysfunction in menopausal women.

\section{Methods}

We performed a prospective, randomized, double-blind, placebo-controlled clinical trial in 74 postmenopausal women with sexual dysfunction. The research was performed at the outpatient clinic of Phytotherapy of the Santa Casa de Misericordia de São Paulo from January 2009 to April 2011. The women who completed the study $(N=60)$ were assigned to two groups. The project was approved by the research ethics committee of the ISCMSP through protocol 008/2009 and registered at www.clinicaltrials.gov under number NCT01407445.
The inclusion criteria were as follows: postmenopausal women, with full autonomy, and at least 1 year of amenorrhea and follicle-stimulating hormone level of $>30 \mathrm{mUI} / \mathrm{mL}$; those who were sexually active; those who had a stable partner and no sexual difficulty; and those who experienced sexual dysfunction after menopause. Women undergoing hormonal therapy; those who did not engage in sexual activity; those with diabetes mellitus, cognitive disorders, a hormone-dependent tumor, current or previous psychiatric disease, liver diseases, except prior cholecystectomy, renal disease, or cardiovascular disease; and those who used drugs that were proven to decrease sexual desire were excluded from the study.

Seventy-four women were initially selected; however, 10 did not fulfill the inclusion and exclusion criteria and 4 discontinued the follow-up subsequently, citing personal reasons (change of city, separation from husband, hospitalization of husband for acute myocardial infarction, and discovery of prostatic pathology in the spouse). After an interview, the women signed an informed consent form and, after randomization, they were divided into two groups. The placebo group $(n=30)$ received placebo in blister packs identical to those of medicinal products (batch 168159): one tablet, orally, three times a day for 90 days. The Tribulus group ( $n=30$ ) received $T$. terrestris as one tablet $(250 \mathrm{mg}$ ) orally three times a day for 90 days.

The questionnaires used in the Sex Interview of the Sexology outpatient clinic of the School of Medical Sciences of Santa Casa de São Paulo, with the purpose of obtaining epidemiological data were the Sexual Quotient-female version (SQ-F), ${ }^{6}$ in addition to the Female Intervention Efficacy Index (FIEI) questionnaire. ${ }^{28}$

The questionnaires were applied individually and by the same researcher. The results were analyzed and interpreted within the theoretical framework of sociohistorical psychology, which is associated with the understanding of the structure of culture, social organization, and the redemption of human subjectivity.

The data obtained in the first interview and in return visits were tabulated and the frequencies were distributed between the groups (placebo and Tribulus groups), according to the variable analyzed. The statistical significance was analyzed by using Student's $t$-test for independent samples comparing the means of the two groups, the chi-square test with Yates correction, the chi-square test, and the Mann-Whitney $U$ test. In all tests, the significance level was set at $5 \%(p<0.05)$. The analysis was performed with the EPI-INFO program for Windows v. 3.3.2 and SPSS software v. 13.0 for Windows.

\section{Results}

The demographic and clinical characteristics of the studied women are presented in -Table 1. There was no significant difference between the groups in age, age at menopause, civil status, race, and religion.

The data from the SQ-F questionnaire that were analyzed at the beginning of the study indicated no significant difference between the placebo and Tribulus groups $(p=0.16)$. After 3 months of treatment, there was a significant 
Table 1 Clinical and demographic characteristics of menopausal women in the placebo group and the Tribulus group

\begin{tabular}{|l|l|l|l|}
\hline Characteristics & Placebo & Tribulus & p Value \\
\hline Age (years) & $54 \pm 5.1$ & $56 \pm 5.8$ & 0.1 \\
\hline Menopausal age (years) & $45 \pm 4.7$ & $47 \pm 5.3$ & 0.1 \\
\hline Civil status & $86.2 \%$ & $93.3 \%$ & 0.3 \\
\hline Married & $13.8 \%$ & $6.7 \%$ & 0.3 \\
\hline Single & $60.0 \%$ & $53.3 \%$ & 0.6 \\
\hline Race & $40.0 \%$ & $46.7 \%$ & 0.6 \\
\hline White & $63.3 \%$ & 65.5 & 0.8 \\
\hline Black and mulatto & $36.7 \%$ & 35.5 & 0.8 \\
\hline Religion &
\end{tabular}

The $\mathrm{p}$ values refer to the outcome of Student's $t$-test for two independent samples $(p<0.05)$. Data are presented as mean \pm standard deviation.

difference between the placebo and Tribulus groups in the domains of desire and sexual interest $(7.6 \pm 3.2$ versus $10.2 \pm 3.2)$ (items 1,2 , and 8$)(p \leq 0.001)$, foreplay $(3.3 \pm 1.5$ versus $4.2 \pm 1.0)$ (item 3$)(\mathrm{p} \leq 0.01)$, arousal in women and harmonious interaction with the partner $(5.7 \pm 2.1$ versus $7.2 \pm 2.6)$ (items 4 and 5$)(\mathrm{p} \leq 0.01)$, and comfort in sexual intercourse $(6.5 \pm 2.4$ versus $8.0 \pm 1.9)$ (items 6 and 7$)(p \leq 0.01)$. In the domains of orgasm and sexual satisfaction (items 9 and 10), there was no significant difference between the placebo and Tribulus groups $(5.2 \pm 2.5$ versus $5.9 \pm 2.6)(p=0.3)(-$ Table 2$)$.

Analysis of the data from the FIEI questionnaire revealed that in item 1 that included vaginal lubrication during coitus and/or foreplay, there was a $20 \%$ improvement in the placebo group and $83.3 \%$ improvement in the Tribulus group after treatment, with a significant difference between the two groups $(p<0.001)$. Concerning the sensation in the genitalia during sexual intercourse or other stimuli (item 2), $16.7 \%$ of women in the placebo group and $76.7 \%$ in the Tribulus group $(p<0.001)$ presented an improvement. In the item "the perception of change in sensation in the genital area" of the FIEI questionnaire (item 3), there was an improvement of $20 \%$ in the placebo group and $70 \%$ in the Tribulus group $(p<0.001)$. Concerning the perception of change in sexual intercourse and/or other sexual stimulations (item 4) after the treatment, $13.3 \%$ in the placebo group evaluated it as pleasant, $56.7 \%$ as unpleasant, and $30 \%$ as indifferent, and in the Tribulus group, $43.3 \%$ evaluated it as pleasant, $16.7 \%$ as unpleasant, and $40 \%$ as indifferent. There was a significant difference between the groups ( $p=0.003$ ). After 3 months of treatment, the analysis of the ability to reach an orgasm (item 5) showed that $73.3 \%$ of the interviewees of the Tribulus group indicated an improvement and $26.7 \%$ reported no change. In the placebo group, $20 \%$ reported an increased ability to have an orgasm and $80 \%$ reported no change $(p<0.001)$ (-Fig. 1).

With regard to the use of the medication (item 7), in the placebo group, $20 \%$ of the women reported an improvement in sexual experience and wished to continue using the medication, $23.3 \%$ did not perceive changes in their sexual experience but wished to continue taking the medication, and $56.7 \%$ reported that their sexual experience was unchanged and they did not want to continue the medication. In the Tribulus group, $80 \%$ reported an improvement in their sexual experience and wanted to continue taking the medication, $10 \%$ reported no change but wished to continue using the medication, and $10 \%$ reported no change and did not wish to continue the medication $(p<0.001)$.

In relation to adverse effects (item 6 ), we observed a greater incidence in the Tribulus group than in the placebo group; the most frequent adverse effects were diarrhea (13.3\%), nervousness (13.3\%), dizziness (10\%), and nausea (10\%) in the Tribulus group, and nervousness (13.3\%), facial flushing (13.3\%), dizziness (10\%), and nausea (10\%) in the placebo group. However, there was no significant difference in relation to the general reference and also to each one of the adverse effects, by overlap of the significance index.

\section{Discussion}

In contrast to male sexual problems, for which many treatment strategies have been formulated, female sexual dysfunction (FSD) remains an area that requires more studies

Table 2 Domains evaluated according to the Sexual Quotient - female version questionnaire before and after the study of the placebo group and the Tribulus group

\begin{tabular}{|l|l|l|l|l|l|l|}
\hline \multirow{2}{*}{ Domains evaluated } & Placebo & \multicolumn{2}{l|}{ Tribulus } & \multicolumn{2}{l|}{ p Value } \\
\cline { 2 - 7 } & Before & After & Before & After & Before & After \\
\hline Desire & $7.5 \pm 3.1$ & $7.6 \pm 3.2$ & $7.4 \pm 3.3$ & $10.2 \pm 3.2$ & 0.7 & 0.001 \\
\hline Foreplay & $2.9 \pm 1.4$ & $3.3 \pm 1.5$ & $3.2 \pm 1.5$ & $4.2 \pm 1.0$ & 0.5 & 0.006 \\
\hline Arousal & $5.2 \pm 2.0$ & $5.7 \pm 2.1$ & $4.9 \pm 2.3$ & $7.2 \pm 2.6$ & 0.6 & 0.006 \\
\hline Comfort & $6.4 \pm 2.3$ & $6.5 \pm 2.4$ & $5.7 \pm 2.8$ & $8.0 \pm 1.9$ & 0.3 & 0.008 \\
\hline Orgasm & $5.2 \pm 2.8$ & $5.2 \pm 2.5$ & $3.6 \pm 2.8$ & $5.9 \pm 2.6$ & 0.01 & 0.2 \\
\hline Total & $54.5 \pm 16.9$ & $56.6 \pm 17.9$ & $49.5 \pm 19.1$ & $70.9 \pm 17.6$ & 0.1 & 0.003 \\
\hline
\end{tabular}

The $\mathrm{p}$ values refer to the outcome of Student's $t$-test for two independent samples $(p<0.05)$. Data are presented as mean \pm standard deviation. 


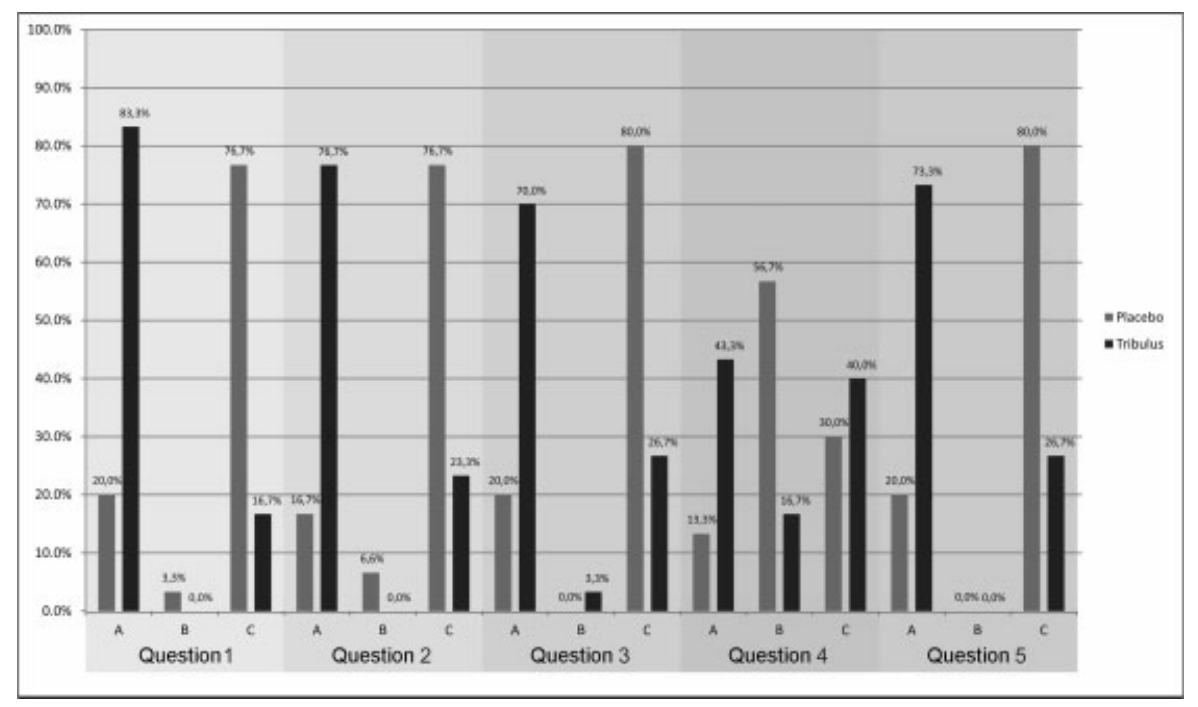

Fig. 1 Female Intervention Efficacy Index: frequency of response to the items as improved (A), worsened (B), indifferent (C). Item 1: Vaginal lubrication during coitus and/or other sexual stimulations (e.g., foreplay) after taking the medication. Item 2: The sensation in genitals (vagina, labia majora, and clitoris) during sexual intercourse or other stimuli (e.g., foreplay) after taking the medication. Item 3: Noticed sensation change in genital area after the study. Item 4: Sexual intercourse and/or other sexual stimulations after taking the medication. Item 5: Ability to have an orgasm after taking the medication.

and clinical trials to identify the most effective treatment option. $^{19}$

The influence of age on sexual desire in both sexes is known, with age-related problems being a particularly frequent complaint among women in the menopausal period. ${ }^{5}$ FSD is the most common complaint in this age group. ${ }^{4}$

To contribute to the management of this condition, we studied the effects of $T$. terrestris, the properties of which have already been tested in men for improving sexual complaints. ${ }^{22}$ Thus, in this study, we aimed to contribute to the study of the effects of $T$. terrestris on the sexuality of women after menopause.

This study was performed because only few studies have focused on phytotherapy for the treatment of $\mathrm{FSD}^{29}$ and no studies have examined the effects of $T$. terrestris on sexual function in menopausal women, which makes this a pioneering study. In fact, the few existing studies are questionable because of a possible conflict of interest and a lack of information about the evaluation instrument. ${ }^{10,23}$

Another relevant issue in the study of female sexuality is the availability of questionnaires for its evaluation. In fact, the great diversity of the instruments used in the study of FSD may reflect the lack of consensus or even the lack of a complete method that allows for a full evaluation of sexual function in all its areas, applicable to all cultures. In our study, we chose to use two questionnaires: a multidimensional questionnaire used in studies developed with a population of Brazilian women (SQ-F) and the FIEI questionnaire (validated for the Portuguese language), a measuring tool with immediate results in medical intervention for treating FSD. ${ }^{5,6}$

When analyzing the domains evaluated by using the SQ-F questionnaire, after 3 months of treatment, we observed a significant improvement in the Tribulus group in the domains of desire and sexual interest ( $p \leq 0.001$ ), foreplay
( $p \leq 0.01)$, arousal and harmonious interaction with partner $(\mathrm{p} \leq 0.01)$, and comfort in sexual intercourse $(\mathrm{p} \leq 0.01)$, when compared with the placebo group.

The results obtained by both questionnaires were concordant with those of published studies that used medications with androgenic effect to evaluate the improvement of sexual response. ${ }^{20-23,25-28}$

When we analyzed the SQ-F, we found that there was no improvement in the domains of orgasm and sexual satisfaction, which are analyzed in items 9 (Are you able to reach orgasmmaximum pleasure-in sexual intercourse?) and 10 (Does the level of satisfaction you achieve from sexual intercourse make you want to engage in sex again on other days?). In fact, in accordance with our findings, no medicinal products have been reported to have a direct action on female orgasm. ${ }^{30}$

Androgens are involved in the sexual response, and their deficit can result in FSD. ${ }^{31}$ Low testosterone levels are associated with a decrease in libido, arousal, genital sensation, and orgasm. ${ }^{11}$ Furthermore, androgens have an important anabolic effect, improving muscle mass, muscular strength, and vigor, which may lead to improvement of sexual desire. ${ }^{25,26}$ Women who received androgen replacement therapy perceived important changes in the level of energy and willingness to work, as well as improvement in their libido. ${ }^{22,25}$

In a randomized, double-blind, placebo controlled study in Europe and Australia that included oophorectomized women with HSDD who used concurrent transdermal estrogen, the group treated with testosterone obtained better scores in the sexual desire domain than the placebo-treated group. The scores in the domains of sexual arousal, orgasm, and responsiveness were significantly higher in the testosterone group. ${ }^{27}$

To evaluate the efficacy and safety of transdermal testosterone $(300 \mu \mathrm{g} /$ day $)$ in naturally menopausal women with 
HSDD, Panay et $\mathrm{al}^{27}$ analyzed 272 women for 6 months in a randomized, multicenter, double-blind, placebo-controlled study, observing an improvement in the domains of sexual desire $(p=0.001)$ and sexual satisfaction $(p=0.01)$.

Steroidal saponins may be responsible for the intrinsic hormonal activity of $T$. terrestris, directly stimulating the endocrine-sensitive female tissues such as the uterus and vagina. ${ }^{19}$ It has been proposed that the active components of $T$. terrestris can be converted enzymatically into weak androgens similar to DHEA, which could, in turn, be converted into more powerful androgens such as testosterone in the gonads and peripheral tissues. ${ }^{13,14,19,20}$

The results of the FIEI questionnaire revealed significant improvement in all variables. There was an improvement of $73.3 \%$ in the ability to reach orgasm $(p<0.001)$ (item 5$)$, in contrast with the results for the domain of orgasm (item 9) of the SQ-F questionnaire. This was probably due to the personal interpretation of each question, thus demonstrating the importance of a critical analysis of the different instruments used. It should be emphasized that the questionnaires were applied by the same researcher to avoid this bias. Another factor to be analyzed is the personal interpretation of each woman, as the questionnaires are self-explanatory.

When we compared the data from the two questionnaires, we observed a concordance after treatment with improvement in the domains of sexual desire, vaginal lubrication, and arousal.

With regard to the placebo group, all items evaluated by using the FIEI questionnaire showed improvement, ranging from 13 to 20\%; nevertheless, the significant difference compared with the Tribulus group was maintained. Bradford and Meston ${ }^{32}$ verified that one-third of women experienced clinically significant improvement in sexual function during treatment with placebo, emphasizing the importance of sexual behavior during the initial interview, in addition to age and the severity of symptoms as important determinants in the result.

The placebo effect does not exist outside the therapeutic context, nor is it limited to specific effects of a medicinal product or compliance with a process. ${ }^{33} \mathrm{~A}$ contextualized view of the placebo effect, in which internal and external factors may promote change in symptoms, provides a broad framework for the understanding of the response to placebo in the treatment of FSD. The existence of what seems to be a placebo response in the population reflects an opportunity to understand the fundamental processes involved in the reduction of the symptoms. ${ }^{32}$ In our study, the data were concordant in relation to the placebo effect, with an improvement in vaginal lubrication, perception of change in the genital region, and in the ability to reach orgasm (13$20 \%$ ).

The study of sexuality in women after menopause is a topic of current and growing interest. Our study aims to contribute to the knowledge on the treatment of sexual dysfunction in this phase of life, by using herbal remedies derived from $T$. terrestris, which may also give rise to new therapeutic perspectives.

\section{Conflict of Interest}

The authors declare no conflict of interest in conducting this study.

\section{Acknowledgments}

We thank the Fundação de Amparo à Pesquisa do Estado de São Paulo (FAPESP) for the financial aid (research funding 2009/02773-1) and the Coordenação de Aperfeiçoamento de Pessoal de Nível Superior (CAPES) for the research fellowship.

\section{References}

1 Kaiser FE. Sexual function and the older woman. Clin Geriatr Med 2003;19(3):463-472, v

2 Santana TGM, Lima SMRR, Silva HFS, Gonçalves N. Fitomedicamentos e sexualidade. In: Lima SMRR. Fitomedicamentos na prática ginecológica e obstétrica. 2a ed. São Paulo, Brazil: Ateneu.; 2009:131-43

3 Laumann EO, Paik A, Rosen RC. Sexual dysfunction in the United States: prevalence and predictors. JAMA 1999;281(6): 537-544

4 Leiblum SR, Koochaki PE, Rodenberg CA, Barton IP, Rosen RC. Hypoactive sexual desire disorder in postmenopausal women: US results from the Women's International Study of Health and Sexuality (WISHeS). Menopause 2006;13(1):46-56

5 Burri A, Hilpert P, Spector T. Longitudinal evaluation of sexual function in a cohort of pre- and postmenopausal women. J Sex Med 2015;12(6):1427-1435

6 Abdo CHN. Elaboração e validação do quociente sexual-versão feminina: uma escala para avaliar a função sexual da mulher. Rev Bras Med 2006;63(9):477-482

7 Lonnèe-Hoffmann RA, Dennerstein L, Lehert P, Szoeke C. Sexual function in the late postmenopause: a decade of follow-up in a population-based cohort of Australian women. J Sex Med 2014; 11(8):2029-2038

8 Schwenkhagen A. Hormonal changes in menopause and implications on sexual health. J Sex Med 2007;4(Suppl 3):220-226

9 Rozenberg S, Gevers R, Peretz A, Vandromme J, Robyn C, Ham H. Decrease of bone mineral density during estrogen substitution therapy. Maturitas 1993;17(3):205-210

10 Davis SR. Androgens and female sexuality. J Gend Specif Med 2000;3(1):36-40

11 Adaikan PG, Gauthaman K, Prasad RN, Ng SC. Proerectile pharmacological effects of Tribulus terrestris extract on the rabbit corpus cavernosum. Ann Acad Med Singapore 2000;29(1):22-26

12 Gauthaman K, Adaikan PG, Prasad RN. Aphrodisiac properties of Tribulus Terrestris extract (Protodioscin) in normal and castrated rats. Life Sci 2002;71(12):1385-1396

13 Gauthaman K, Ganesan AP. The hormonal effects of Tribulus terrestris and its role in the management of male erectile dysfunction-an evaluation using primates, rabbit and rat. Phytomedicine 2008;15(1-2):44-54

14 Shamloul R. Natural aphrodisiacs. J Sex Med 2010;7(1 Pt 1):39-49

15 De Combarieu E, Fuzzati N, Lovati M, Mercalli E. Furostanol saponins from Tribulus terrestris. Fitoterapia 2003;74(6): 583-591

16 Kostova I, Dinchev D. Saponins in Tribulus terrestris-chemistry and bioactivity. Phytochem Rev 2005;4(2):111-137

17 Sun W, Gao J, Tu G, Guo Z, Zhang Y. A new steroidal saponin from Tribulus terrestris Linn. Nat Prod Lett 2002;16(4):243-247

18 Nian H, Qin LP, Chen WS, Zhang QY, Zheng HC, Wang Y. Protective effect of steroidal saponins from rhizome of Anemarrhena 
146 Assessment of the Effects of Tribulus terrestris on Sexual Function of Menopausal Women Postigo et al.

asphodeloides on ovariectomy-induced bone loss in rats. Acta Pharmacol Sin 2006;27(6):728-734

19 Mazaro-Costa R, Andersen ML, Hachul H, Tufik S. Medicinal plants as alternative treatments for female sexual dysfunction: utopian vision or possible treatment in climacteric women? J Sex Med 2010;7(11):3695-3714

20 Arsyad KM. Effect of protodioscin on the quantity and quality of sperms from males with moderate idiopathic oligozoospermia. Medika 1996;22(8):614-618

21 Adimoelja A. Phytochemicals and the breakthrough of traditional herbs in the management of sexual dysfunctions. Int J Androl 2000;23(Suppl 2):82-84

22 Neychev VK, Mitev VI. The aphrodisiac herb Tribulus terrestris does not influence the androgen production in young men. J Ethnopharmacol 2005;101(1-3):319-323

23 Akhtari E, Raisi F, Keshavarz M, et al. Tribulus terrestris for treatment of sexual dysfunction in women: randomized double-blind placebo - controlled study. Daru 2014;22:40

24 Yialamas MA, Hayes FJ. Androgens and the ageing male and female. Best Pract Res Clin Endocrinol Metab 2003;17(2): 223-236

25 Mameri Filho J, Haidar MA, Soares Junior JM, Baracat EC. Effects of the association of estrogen and androgen in postmenopausal women. Rev Bras Ginecol Obstet 2005;27(3): 118-124
26 Davis SR, van der Mooren MJ, van Lunsen RH, et al. Efficacy and safety of a testosterone patch for the treatment of hypoactive sexual desire disorder in surgically menopausal women: a randomized, placebocontrolled trial. Menopause 2006;13(3):387-396

27 Panay N, Al-Azzawi F, Bouchard C, et al. Testosterone treatment of HSDD in naturally menopausal women: the ADORE study. Climacteric 2010;13(2):121-131

28 Berman LA, Berman JR, Werbin T, Chabra S, Goldstein I. The use of the Female Intervention Efficacy Index (FIEI) as an immediate outcome measure of medical intervention to treat female sexual dysfunction. J Sex Marital Ther 2001;27(5):427-433

29 Rowland D, Tai W. A review of plant-derived and herbal approaches to the treatment of sexual dysfunctions. J Sex Marital Ther 2003;29(3):185-205

30 Al-Azzawi F, Bitzer J, Brandenburg U, et al. Therapeutic options for postmenopausal female sexual dysfunction. Climacteric 2010; 13(2):103-120

31 Bancroft J. The endocrinology of sexual arousal. J Endocrinol 2005;186(3):411-427

32 Bradford A, Meston CM. Behavior and symptom change among women treated with placebo for sexual dysfunction. J Sex Med 2011;8(1):191-201

33 Price DD, Finniss DG, Benedetti F. A comprehensive review of the placebo effect: recent advances and current thought. Annu Rev Psychol 2008;59:565-590 